Österr Wasser- und Abfallw $2020 \cdot 72: 92-93$

https://doi.org/10.1007/s00506-019-00643-x

\title{
Erratum zu: Bromierte Flammschutzmittel in Elektro- altgeräten: Untersuchung der Brom-Konzentration nach Kunststofftypen und Gerätekategorienmittels Röntgenfluoreszenzanalyse
}

Aleksander Jandric · Florian Part · Niklas Fink · Marion Huber-Humer · Stefan Salhofer · Christian Zafiu

Online publiziert: 3. Dezember 2019

(C) Österreichischer Wasser- und Abfallwirtschaftsverband (ÖWAV) and Springer-Verlag GmbH Austria, ein Teil von Springer Nature 2019

\section{Erratum zu:}

Österr Wasser- und Abfallw 2019

https://doi.org/10.1007/s00506-019-

00639-7

Leider befindet sich in Abb. 4 ein Fehler. Sie finden die korrigierte Beschriftung der Ordinate von Bild (b) hier:

Die Online-Version des

Originalartikels ist unter https://doi. org/10.1007/s00506-019-00639-7 zu finden.

DI A. Jandric .

DI Dr. F. Part $(\bowtie) \cdot$ DI N. Fink .

Univ.-Prof. DI Dr. M. Huber-Humer .

ao. Univ.-Prof. DI Dr. S. Salhofer .

Mag. Dr. C. Zafiu

Department für Wasser-

Atmosphäre-Umwelt, Institut für

Abfallwirtschaft (ABF-BOKU),

Universität für Bodenkultur Wien,

Muthgasse 107, 1190 Wien, Österreich

florian.part@boku.ac.at 


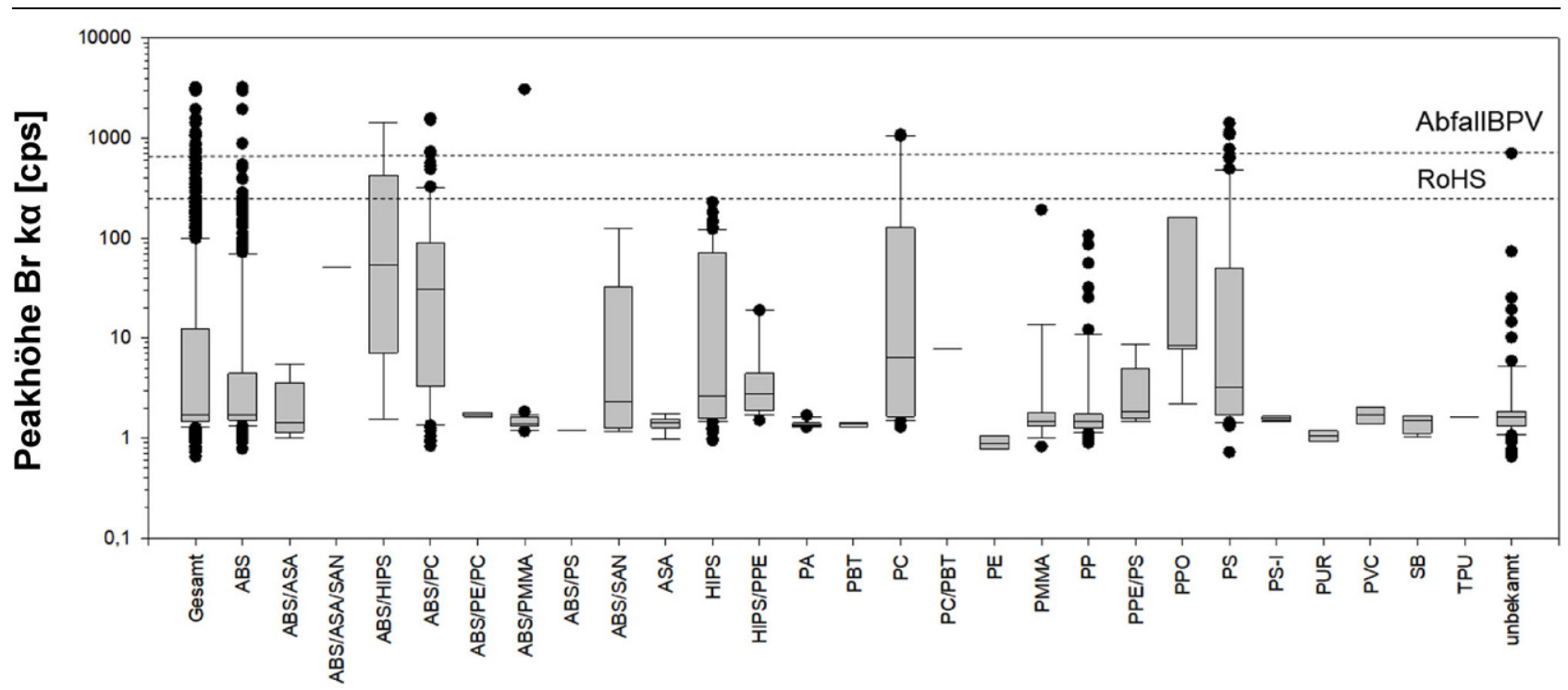

a

Kunststofftyp

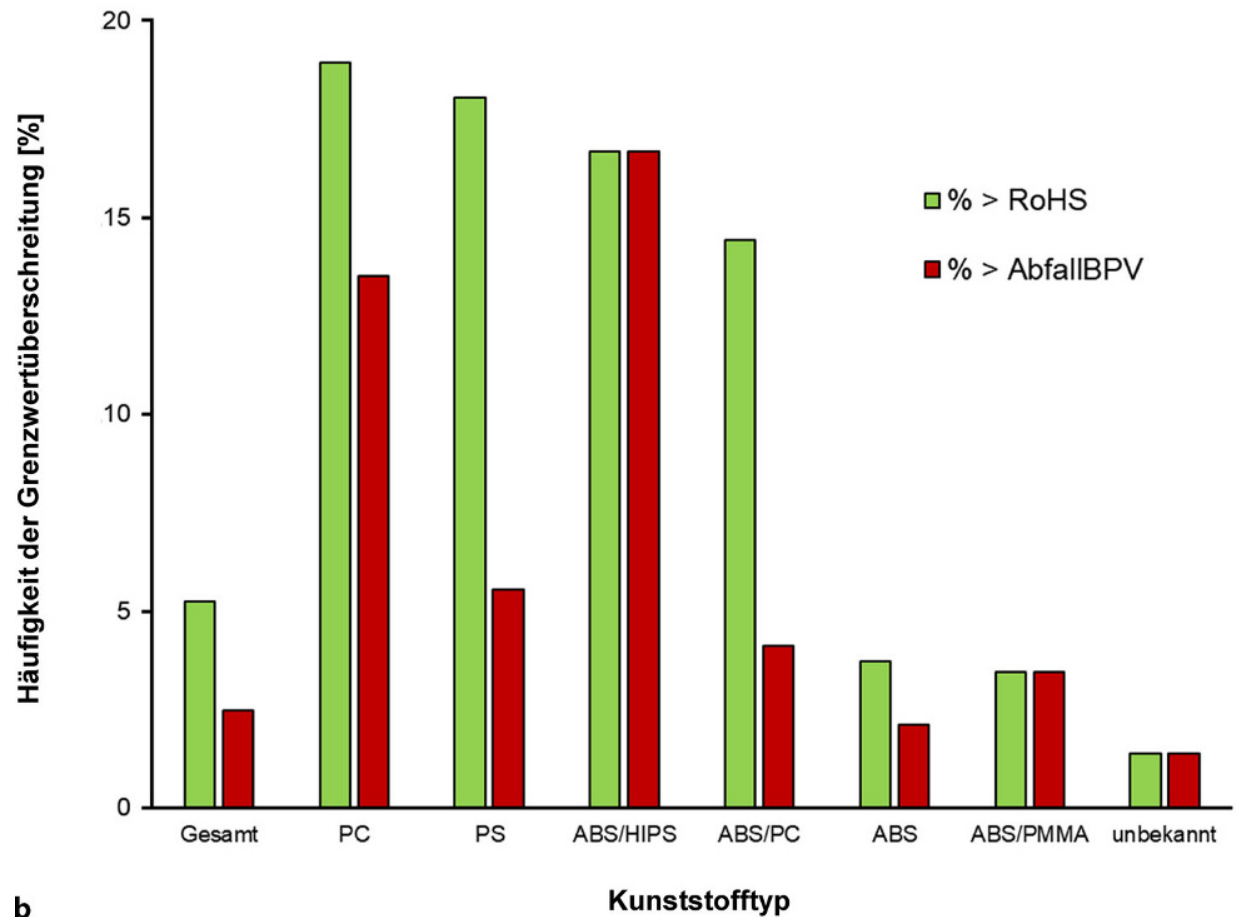

Abb. 4 Verteilung des Gesamtbromgehaltsund Überschreitung derGrenzwerte in Abhängigkeitvom Kunststofftyp. Bild(a)zeigtanhand von Box-Plot-Diagrammen die Bromverteilung im gesamten Probenumfang (Gesamt) sowie in den einzelnen Kunststofftypen, die in den untersuchten EAG-Kategorien gefunden wurden. Die grauen Boxen stellen die Verteilung von 25 bis $75 \%$ aller Messdaten und die horizontalen Linien innerhalb der Boxen den Median dar. Die Antennen (Whisker) stellen die Verteilung von 10 bis $90 \%$ aller Messdaten um den Median dar. Oberhalb und unterhalb der Whisker sind die Ausreißer der Messdaten als Kreise abgebildet. Die gestrichelten horizontalen Linien stellen die in cps umgerechneten Grenzwerte gemäß RoHS und AbfallBPV zur Orientierung dar. In Bild (b) ist der prozentuelle Anteil jener Kunststofftypen ersichtlich, der über dem RoHS- (grün) oder AbfallBPV-Grenzwert (rot) liegen. In diesem Bild sind somit jene 20 Kunststofftypen nicht enthalten, in denen die Grenzwerte unterschritten wurden 